\title{
Influence of Bilirubin on Human Platelets
}

\author{
Harold M. Maurer ${ }^{[54]}$ and Joyce Gaul \\ Department of Pediatrics, Medical College of Virginia, Health Sciences Division, Virginia Commonwealth University, \\ Richmond, Virginia, USA
}

\begin{abstract}
Extract
Studies were performed which showed that unbound unconjugated bilirubin at low concentration $(0.5 \mathrm{mg} / 100 \mathrm{ml})$ causes yellow staining and aggregation of washed human platelets, whereas bilirubin bound to albumin and bilirubin altered by exposure to light have little, if any, of these effects on platelets. Less intense aggregation occurred in some but not all samples of platelet-rich plasma incubated with bilirubin and only at bilirubin levels of $10 \mathrm{mg} / 100 \mathrm{ml}$ or higher. Aggregation of platelets by bilirubin showed an absolute requirement for calcium ions and this response was enhanced by potassium ions. Adenosine diphosphate and adenosine triphosphate were released from platelets with bilirubin.
\end{abstract}

\section{Speculation}

In the early accounts of human kernicterus, and in studies of experimental hyperbilirubinemia in animals, hemorrhagic complications were well known but poorly understood. The data presented suggest that bilirubin influences platelet function. It is tempting to speculate that the effect of bilirubin on platelets could play a role in producing intravascular thrombosis or hemorrhage, or both, in severe hyperbilirubinemia.

\section{Introduction}

The cytotoxicity in vitro of unconjugated bilirubin on a variety of tissues including brain [9, 27], liver mitochondria [38], and mammalian erythrocytes [5, 21, 30] is well documented. Bilirubin also produces severe neurologic damage in living animals $[2,10,33,35]$ and in man [1]. Rozdilsky [32, 33] has shown that infusion of bilirubin in newborn and adult animals (dogs, rabbits, cats, and rats) causes not only kernicterus but hemorrhage in the intestines as well as other sites. Although it is well established that bilirubin inhibits respiration and uncouples oxidative phosphorylation in isolated mitochondria and brain homogenates $[8,9$, $27,34,38]$, the mechanism of pigment toxicity in vivo is not known [11].

Recently, it has been shown with light microscopy that washed human platelets change morphologically following their incubation with unbound unconjugated bilirubin at concentrations of $15 \mathrm{mg} / 100 \mathrm{ml}$ or higher [36]. These changes include yellow staining, swelling, filamentous membrane formation, platelet aggregation, and cell lysis. When platelets are pretreated with unbound unconjugated bilirubin (15 $\mathrm{mg} / 100 \mathrm{ml}$ or higher) and used in thromboplastin generation tests, impaired generation is noted [36]. The addition of bilirubin (15 mg/100 $\mathrm{ml}$ or higher) to whole blood also impairs clot retraction [36]. The mechanisms underlying these platelet changes are not known. The clinical significance of these findings with respect to platelet function in vivo in the presence of bilirubin is also not known. However, Rozdilsky's observation $[32,33]$ that bilirubin infusion in animals 
causes a hemorrhagic diathesis suggests that these platelet changes may be of clinical importance.

Since a variety of clinical factors (e.g., drugs [6, 23] and liver disease [19]) may influence platelet functions in jaundiced patients, any conclusions drawn from clinical studies regarding the action of bilirubin on platelets must be made cautiously. Further clarification of its in vitro action is required.

Our purposes were to study bilirubin-induced platelet aggregation under a variety of conditions in vitro, using a sensitive, recently developed spectrophotometric technique [4], and to determine the effect of bilirubin on platelet adenine nucleotide content.

\section{Methods}

\section{Collection of Blood}

Venous blood for platelet studies was collected with a disposable needle and syringe from healthy adult laboratory volunteers, and was mixed 9:1 with $1 \%$ sodium ethylenediaminetetraacetate (EDTA) in $0.7 \%$ saline or with $4 \%$ citrate solution. None of the donors had ingested any medication for at least 2 weeks prior to the collection. Platelet-rich plasma, which contained $330,000-550,000$ platelets $/ \mathrm{mm}^{3}$, was obtained by centrifugation at $600 \mathrm{rpm}$ [40] for $15 \mathrm{~min}$ at $4^{\circ}$ or at room temperature. Plastic disposable test tubes and siliconized [41] glassware were used. Tests were accomplished within $3 \mathrm{hr}$ of blood collection and the time for each group of studies, with and without bilirubin, was approximately equal.

\section{Preparation of Platelet Suspensions}

Studies were performed either on washed platelets in suspension prepared from blood collected in EDTA solution or on citrated platelet-rich plasma. Washed platelets in suspension were prepared as follows [15]. A platelet pellet was obtained from EDTA-platelet plasma by centrifugation at $3000 \mathrm{rpm}$ for $15 \mathrm{~min}$ at $4^{\circ}$ or at room temperature. Platelets were washed twice with a mixture composed of $0.154 \mathrm{M}$ sodium chloride, $0.154 \mathrm{M}$ Tris-hydrochloride buffer ( $\mathrm{pH} 7.4$ ) [42], and 1\% EDTA mixed in the proportions of 90:8:2 v/v/v, and then resuspended in Tris-buffered saline, $\mathrm{pH} 7.8$.

\section{Platelet Aggregation Studies}

Platelet aggregation was studied spectrophotometrically using a platelet aggregometer [43] connected to a recorder [44]. This method is now widely employed for studies of platelet aggregation $[4,23,26]$.
Changes in light transmission were recorded continuously. As platelets aggregate in a sample of platelet suspension or platelet-rich plasma, the solution becomes increasingly clearer and the amount of light transmitted through the sample increases, causing a positive or upward deflection of the recorder pen. The slope of the curve allows estimation of the rate of aggregation, while the course, maximal height, and return to base line provide information concerning the relative responsiveness of a given patient's platelets to a variety of stimuli. The amplitude of each oscillation in the record is roughly proportional to the aggregate size. Platelets in suspension or in plasma were stirred continuously at $900 \mathrm{rpm}$ and allowed to equilibrate for $5 \mathrm{~min}$ at $37^{\circ}$ before the addition of bilirubin or other solutions.

Solutions $(0.1 \mathrm{ml})$ of bilirubin (final concentration $0.5-24 \mathrm{mg} / 100 \mathrm{ml}$ ), bilirubin-albumin mixtures, albumin, and photooxidized bilirubin were added cither to washed platelet suspension $(0.4 \mathrm{ml})$ mixed with $0.154 \mathrm{M} \mathrm{KCl}(0.05 \mathrm{ml})$ and $0.11 \mathrm{M} \mathrm{CaCl}_{2}(0.02 \mathrm{ml})$ or to citrated platelet-rich plasma $(0.4 \mathrm{ml})$; changes in light transmission were recorded. A drop of platelet suspension or platelet-rich plasma was placed on a glass slide and examined under the light microscope before and after treatment with solutions of bilirubin and albumin. Experiments were performed in triplicate at least.

\section{Preparation of Bilirubin and Albumin Solutions}

Bilirubin solution was prepared by dissolving crystalline bilirubin [45] in $0.5 \mathrm{~N} \mathrm{NaOH}$, and adding 0.154 M Tris-hydrochloride buffer ( $\mathrm{pH} 7.8$ ) to the desired concentration. A sample was removed for estimation of bilirubin concentration [22] and then the stock solution was stored up to 1 week at $-20^{\circ}$ in the dark until use. Desired concentrations of bilirubin solution were prepared by diluting the stock solution with buffer, $\mathrm{pH}$ 7.8. All experiments with bilirubin solution were performed in the dark to avoid photooxidation of the material.

Serum albumin solutions were prepared by diluting normal human serum albumin (salt-poor) [46] with Tris-buffered saline, pH 7.8. The protein content of the stock solution was determined by the micro-Kjeldahl method [20]. One molar bilirubin/albumin ratio is equivalent to approximately $8 \mathrm{mg}$ bilirubin $/ \mathrm{g}$ albumin [28]. Five-tenths milliliter of each of several prepared bilirubin solutions were added to $0.5 \mathrm{ml}$ of the albumin solution to achieve the following proportions: $6 \mathrm{mg}$ bilirubin/g albumin (molar ratio bilirubin/al- 
bumin, 0.75 ); $12 \mathrm{mg}$ bilirubin/g albumin (molar ratio bilirubin/albumin, 1.5); $18 \mathrm{mg}$ bilirubin/g albumin (molar ratio bilirubin/albumin, 2.25); $20 \mathrm{mg}$ bilirubin/gram albumin (molar ratio bilirubin/albumin, 2.5 ); and $24 \mathrm{mg}$ bilirubin/g albumin (molar ratio bilirubin/albumin, 3.0). The final $\mathrm{pH}$ of the solutions added to the platelet preparations was 7.8.

Bilirubin solutions were exposed to $200 \mathrm{ft}-\mathrm{c}$ blue light (eight 20-w fluorescent lamps [47]) for periods of 4 , 24, and $48 \mathrm{hr}$. The lamps had been in use for less than $200 \mathrm{hr}$ and the distance from lamps to specimen was $40 \mathrm{~cm}$. According to the manufacturers, the energy output at the surface of a new lamp is $3.3 \mathrm{w}$ and after $200 \mathrm{hr}$ of use it is down to $83 \%$ of this value [7]. The absorption spectrum (190-800 mU) of each solution of photooxidized bilirubin was then determined in a ratio-recording spectrophotometer [48]. The effect of each solution on platelets was determined in the manner described above.

\section{Adenine Nucleotide Assays}

Adenine nucleotides were assayed in platelets and supernatant fluids containing released platelet nucleotides. Washed platelets obtained from $3 \mathrm{ml}$ platelet suspension were resuspended in a solution composed of Tris-buffered saline ( $\mathrm{pH} 7.8,0.85 \mathrm{ml}), 0.154 \mathrm{M} \mathrm{KCl}$ $(0.1 \mathrm{ml}), 0.11 \mathrm{M} \mathrm{CaCl}_{2}(0.05 \mathrm{ml})$, and either bilirubin solution (final concentration $6 \mathrm{mg} / 100 \mathrm{ml}(0.1 \mathrm{ml})$ ), bilirubin-albumin solution (molar ratio $0.75(0.1 \mathrm{ml})$ ), or Tris-buffered saline $(\mathrm{pH} 7.8(0.1 \mathrm{ml}))$. Mixtures were incubated at room temperature for $10 \mathrm{~min}$ and then centrifuged. Supernatant fluid containing released adenine nucleotides was removed, and $\mathrm{I} \mathrm{ml}$ was mixed with an equal volume of $4 \% \mathrm{HClO}_{4}$. Platelets were washed twice in Tris-buffered saline, $\mathrm{pH} 7.8$, and were resuspended in $2 \mathrm{mI} 4 \% \mathrm{HClO}_{4}$. Mixtures were incubated for $10 \mathrm{~min}$ in an ice bath and then centrifuged. The deproteinized supernatant fluid $(1.8 \mathrm{ml})$ from each mixture was then added to $0.6 \mathrm{ml} 0.8 \mathrm{M}$ Tris, adjusted to $\mathrm{pH} 9.8$ with $\mathrm{HCl}$, containing $1 \mathrm{M}$ $\mathrm{K}_{2} \mathrm{CO}_{3}$ and was placed in an ice bath for $15 \mathrm{~min}$. The precipitated $\mathrm{KClO}_{4}$ in each sample was removed by centrifugation and the supernatant fluid, whose $\mathrm{pH}$ was $7.5 \pm 0.2$, was assayed for adenosine diphosphate (ADP) or adenosine triphosphate (ATP).

Adenosine diphosphate and ATP were assayed by modifying the Boehringer [49] and Sigma [50] enzymatic methods, respectively, for determining ADP and ATP in whole blood. To perform the ADP assay, we mixed $2 \mathrm{ml}$ test supernatant fluid in a cuvette $(1-\mathrm{cm}$ light path) with $0.15 \mathrm{ml} 0.01 \mathrm{M}$ phosphoenolpyruvate,
$0.03 \mathrm{ml} 0.009 \mathrm{~m} \mathrm{NADH}, 0.02 \mathrm{ml}$ lactic dehydrogenase ( $1 \mathrm{mg} / \mathrm{ml}$ ), and $0.07 \mathrm{ml}$ distilled water for $5 \mathrm{~min}$. Pyruvate kinase $(0.02 \mathrm{ml}, 1 \mathrm{mg} / \mathrm{ml})$ was then added and the change in optical density at $340 \mathrm{~m} \mu$ after $5 \mathrm{~min}$, owing to removal of reduced nicotinamide adenine dinucleotide $(\mathrm{NADH})$, was determined with a Beckman spectrophotometer.

To perform the ATP assay, $2 \mathrm{ml}$ test supernatant fluid were mixed in a vial with $0.3 \mathrm{mg} \beta$-NADH. The contents of the vial were poured into a cuvette $(1-\mathrm{cm}$ light path). A 0.04-ml sample of a mixture of glyceraldehyde phosphate dehydrogenase $(1 \mathrm{mg} / \mathrm{ml}$ ) and phosphoglyceric phosphokinase $(1 \mathrm{mg} / \mathrm{ml})$ was then added and the change in optical density at $340 \mathrm{~m} \mu$ after $5 \mathrm{~min}$, owing to removal of $\mathrm{NADH}$, was determined with a Beckman spectrophotometer. A calibration curve for each nucleotide was prepared by performing the assay on a solution composed of Tris-buffered saline, $\mathrm{KCl}$, and $\mathrm{CaCl}_{2}$ to which known amounts of ADP and ATP were added. Results were expressed as nanomoles of ADP or ATP per $10^{9}$ platelets. Recovery of adenine nucleotides added to platelet suspension or supernatant fluids was $87-100 \%$.

\section{Results}

The comparative responses of washed platelets and platelet-rich plasma with bilirubin are illustrated in Figure 1. The responses of platelets prepared at room temperature were identical to those prepared at $4^{\circ}$. Washed platelets were extensively aggregated and heavily stained with bilirubin when the bilirubin concentration was as low as $0.5 \mathrm{mg} / 100 \mathrm{ml}$. In contrast, only weak aggregation occurred in 6 of 10 samples of platelet-rich plasma and only at bilirubin levels of 10 $\mathrm{mg} / 100 \mathrm{ml}$ or higher. These bilirubin-aggregating effects were easily reproducible. These findings suggest that plasma components, probably proteins, inhibit the action of bilirubin on platelets.

Figure 2 shows, at $\times 400$ magnification, unstained washed platelets before the addition of bilirubin. Figure 3, at the same magnification, shows clumps of platelets stained yellow with bilirubin (final concentration, $4 \mathrm{mg} / 100 \mathrm{ml}$ ). Stained platelets washed twice in Tris-buffered saline, pH 7.8, remained pigmented.

Figure 4 illustrates the effect of albumin on bilirubin-induced platelet aggregation. Normally, 1 mole of albumin binds 2 moles of bilirubin [28, 31]. When all the bilirubin presumably was bound to albumin, i.e., at bilirubin/albumin molar ratios below 2, aggregation and staining were abolished. When the saturation 
of albumin with bilirubin was exceeded and, presumably, free bilirubin was present (bilirubin/albumin molar ratios above 2), platelet aggregation and stain- ing were seen. However, for reasons unclear at the present time, concentrations of what we would believe to be free bilirubin of more than $0.5 \mathrm{mg} / 100 \mathrm{ml}$ failed

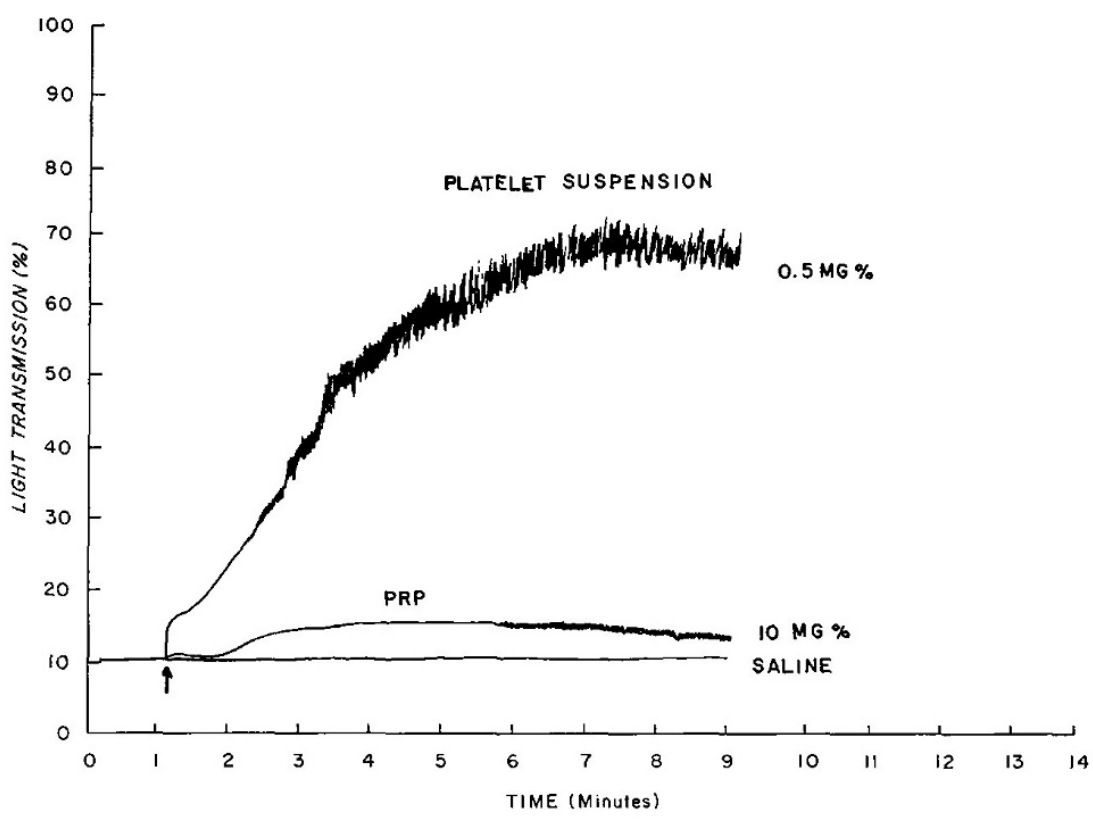

Fig. 1. The effect of bilirubin on washed platelets and platelet-rich plasma (PRP). Platelet suspension (0.4 $\mathrm{ml})$ was incubated for $5 \mathrm{~min}$ at $37^{\circ}$ with $0.05 \mathrm{mI} \mathrm{KCl}(0.154 \mathrm{M})$ and $0.02 \mathrm{ml} \mathrm{CaCl}_{2}(0.11 \mathrm{M})$ before the addition (indicated by the arrow) of $0.1 \mathrm{ml}$ bilirubin (final concentration $0.5 \mathrm{mg} / 100 \mathrm{ml}$ ) or Tris-buffered saline, $\mathrm{pH} 7.8$. Platelet-rich plasma $(0.4 \mathrm{ml})$ was incubated for 5 min at $37^{\circ}$ before the addition of $0.1 \mathrm{ml}$ bilirubin (final concentration $10 \mathrm{mg} / 100 \mathrm{ml}$ ) or Tris-buffered saline, $\mathrm{pH}$ 7.8. Light transmission is directly proportional to platelet aggregation.

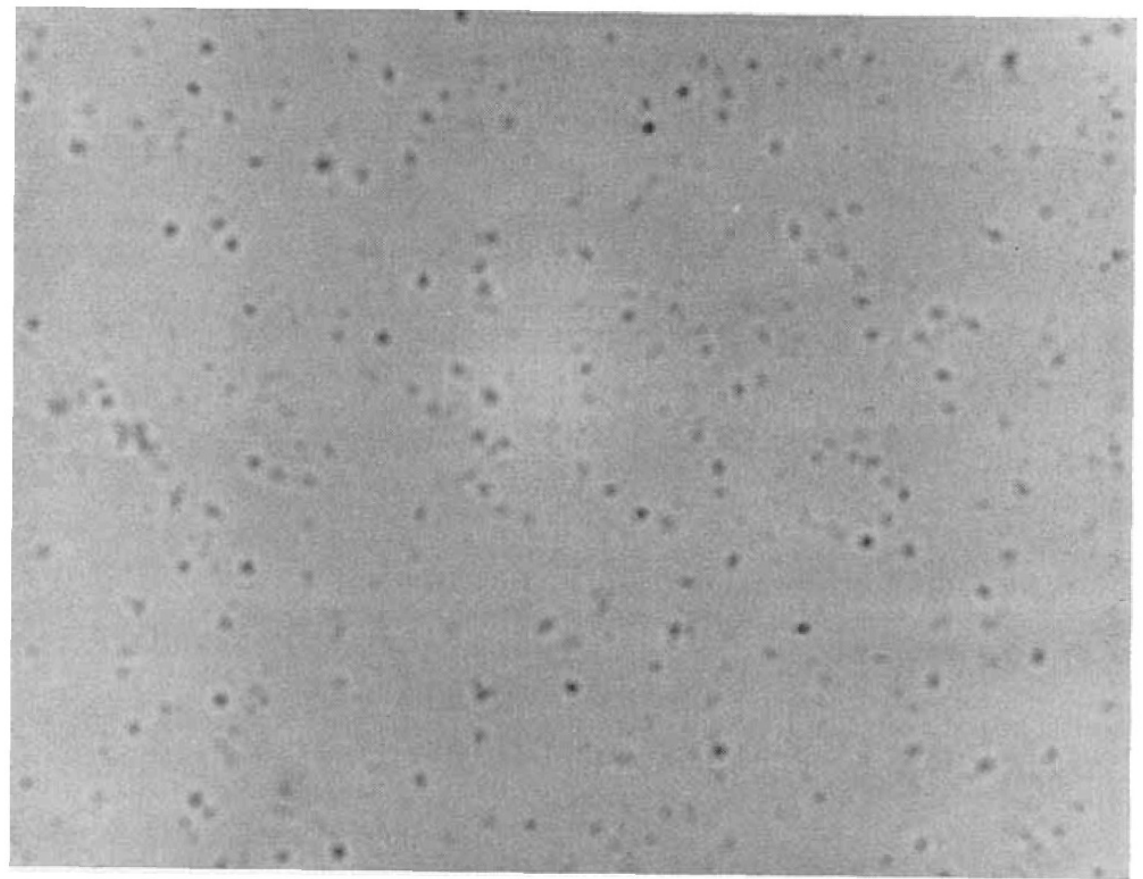

Fig. 2. Platelet suspension $(0.4 \mathrm{ml})$ was incubated for $5 \mathrm{~min}$ at $37^{\circ}$ with $0.05 \mathrm{ml} \mathrm{KCl}(0.154 \mathrm{M}), 0.02 \mathrm{ml} \mathrm{CaCl} 2(0.11 \mathrm{M})$, and $0.1 \mathrm{ml} \mathrm{Tris-}$ buffered saline $(\mathrm{pH} 7.8)$, and then viewed at $\times 400$ magnification with a light microscope. 


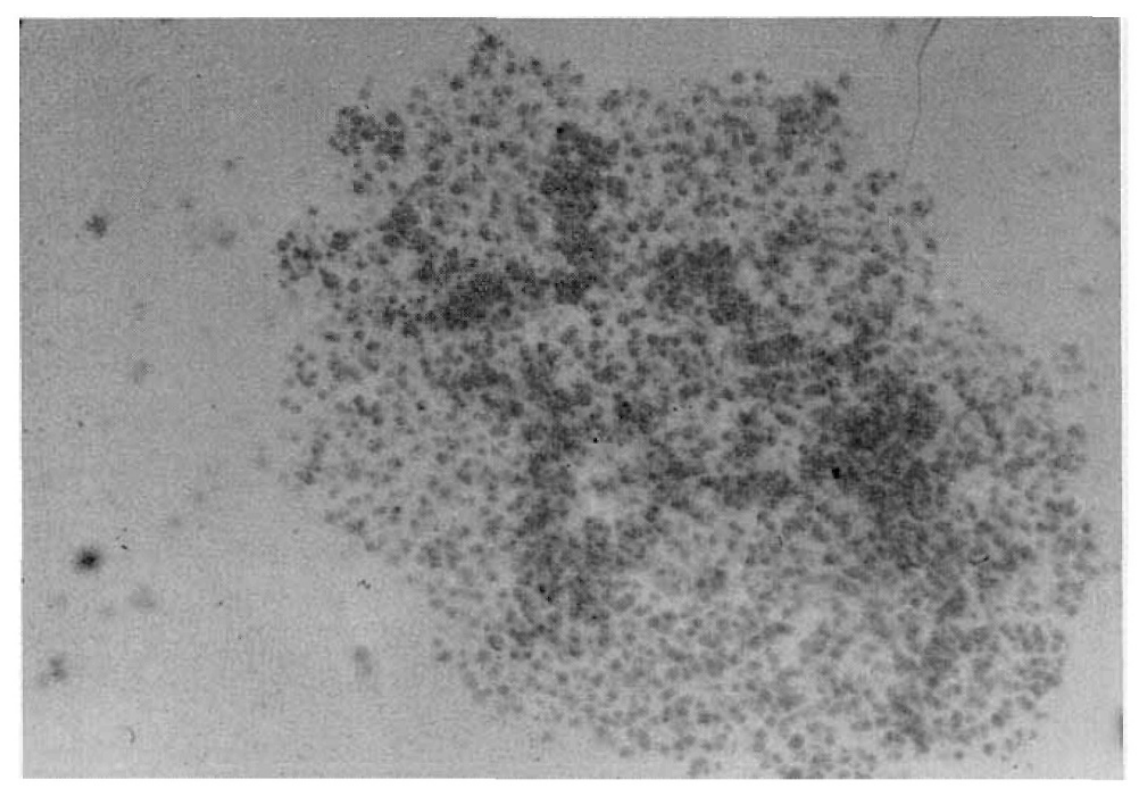

Fig. 3. The platelet suspension shown in Figure 2 was incubated with $0.1 \mathrm{ml}$ bilirubin (final concentration $4 \mathrm{mg} / 100 \mathrm{ml}$ ) in place of Trisbuffered saline, and then viewed at $\times 400$ magnification with a light microscope. Platelet clumps and single platelets are stained yellow.

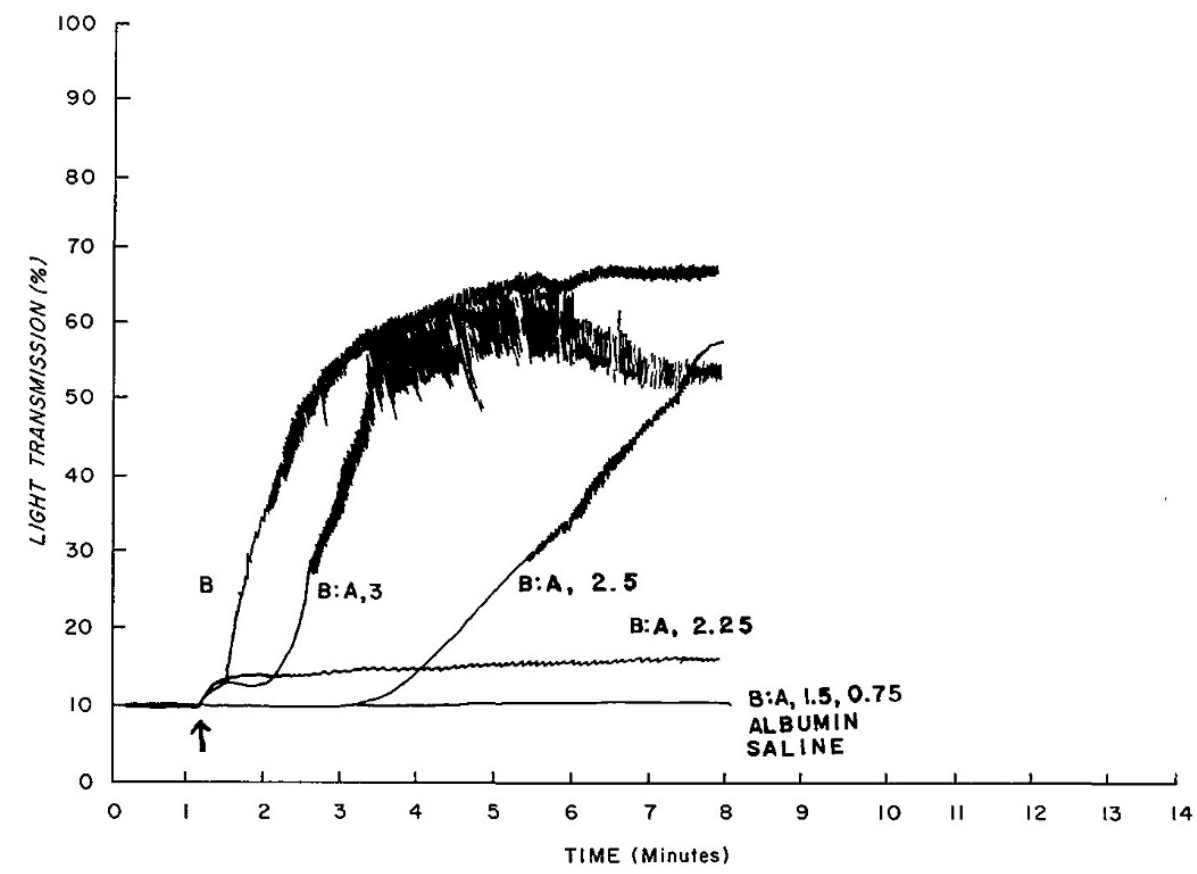

Fig. 4. The effect of albumin on aggregation of platelets with bilirubin. Platelet suspension $(0.4 \mathrm{ml})$ was incubated for 5 min at $37^{\circ}$ with $0.05 \mathrm{ml} \mathrm{KCl}(0.154 \mathrm{M})$ and $0.02 \mathrm{ml} \mathrm{CaCl}_{2}(0.11 \mathrm{~m})$ before the addition (indicated by the arrow) of $0.1 \mathrm{ml}$ of bilirubin (B, final concentration $6 \mathrm{mg} / 100 \mathrm{ml}$ ), albumin (final concentration $1 \mathrm{~g} / 100 \mathrm{ml}$ ), mixtures of bilirubin and albumin (B:A) (molar ratios B/A: 0.75, 1.5, 2.25, 2.5, 3.0), or Tris-buffered saline, $\mathrm{pH}$ 7.8. Light transmission is directly proportional to platelet aggregation.

to have the same effect as truly free bilirubin of that concentration in the complete absence of albumin.

Bilirubin was exposed to $200 \mathrm{ft}-\mathrm{c}$ blue fluorescent light for periods of 4,24 , and $48 \mathrm{hr}$. The alkaline aqueous solution of bilirubin shortly after preparation had a maximal absorption of about $430 \mathrm{~m} \mu$. During exposure to light there was a marked progressive decrease in optical density at this wavelength. After $4 \mathrm{hr}$ 


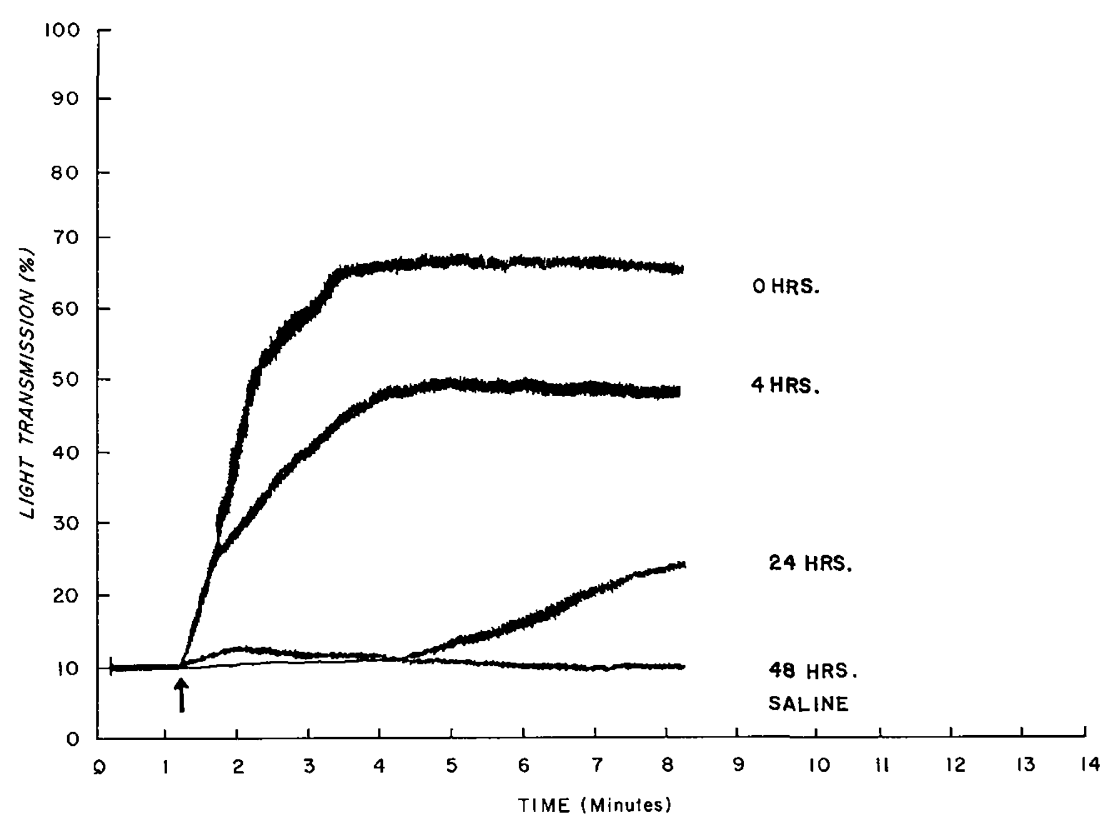

Fig. 5. Platelet aggregation by solutions of bilirubin which were previously exposed to $200 \mathrm{ft}-\mathrm{c}$ blue light for $0,4,24$, and $48 \mathrm{hr}$. Platelet suspension $(0.4 \mathrm{ml})$ was incubated for $5 \mathrm{~min}$ at $37^{\circ}$ with $0.05 \mathrm{ml} \mathrm{KCl}(0.154 \mathrm{M})$ and $0.02 \mathrm{ml} \mathrm{CaCl}{ }_{2}(0.11 \mathrm{M})$ before the addition (indicated by the arrow) of $0.1 \mathrm{ml}$ bilirubin solution (final concentration $4 \mathrm{mg} / 100 \mathrm{ml}$ before exposure to light) or Tris-buffered saline, $\mathrm{pH} 7.8$. Light transmission is directly proportional to platelet aggregation.

of exposure there was an increase in optical density at $660 \mathrm{~m} \mu$, the wavelength at which the concentration of biliverdin is determined spectrophotometrically, and the solution had a definite greenish tinge. In addition, the absorption peak shifted to $400 \mathrm{~m}_{\mu}$. After 24 and 48 $\mathrm{hr}$, the initial absorption peak at $430 \mathrm{~m}_{\mu}$ had disappeared but a distinct hump had appeared at $370 \mathrm{~m} \mu$, probably owing to production of bilirubin derivatives. These results are in accord with those described by Blondheim and associates [3] under similar conditions. The approximate bilirubin concentration in the sample exposed to light for $24 \mathrm{hr}$ was $0.3 \mathrm{mg} / 100 \mathrm{ml}$. Platelet responses to these photooxidized bilirubin soIutions (final concentration of bilirubin before light exposure, $4 \mathrm{mg} / 100 \mathrm{ml}$ ) are illustrated in Figure 5 . With increasing duration of light exposure, the solutions became progressively less active and after $48 \mathrm{hr}$ they had lost their capacity to induce platelet aggregation. It should be recognized that exposure of bilirubin to alkaline solutions for hours or days may result in degradation of bilirubin to other tetrapyrroles, even in the dark. Therefore, the change to a nontoxic material is not necessarily due to photooxidation alone.

The effect of ionic composition of the medium on aggregation induced by bilirubin is shown in Figure 6 . The most rapid and extensive aggregation was found when the suspension of platelets was supplemented with both calcium and potassium. Aggregation showed an absolute requirement for calcium ions and this response was enhanced by potassium ions. In contrast, all platelet suspensions, regardless of their ionic composition, showed intense platelet staining. Platelet staining can occur without aggregation.

Studies were performed to determine whether platelet aggregation by bilirubin was associated with any change in concentration of platelet adenine nucleotides. Table $I$ shows the results. In the presence of bilirubin, ADP and ATP were released from the platelets. Released ADP and ATP were present in the supernatant fluids. Bilirubin bound to albumin at a molar ratio of 0.75 had no effect on platelet content of these nucleotides.

\section{Discussion}

The phenomenon of platelet aggregation has received a great deal of attention since Hellem [18] and others $[4,13]$ showed that ADP in physiologic amounts causes rapid aggregation of platelets. It is now believed that platelet aggregation in response to ADP is the biochemical mechanism underlying platelet plug formation in hemostasis and thrombosis. Calcium ions are essential to this phenomenon. Not only ADP, but collagen, thrombin, and a large variety of biologic and 
nonbiologic substances elicit the same response [23]. Platelets exposed to these agents release certain platelet components in the supernatant fluid. Among these are preformed ADP [16, 17]. It is now believed that aggregation induced by these agents is due to released intra-platelet ADP [17].

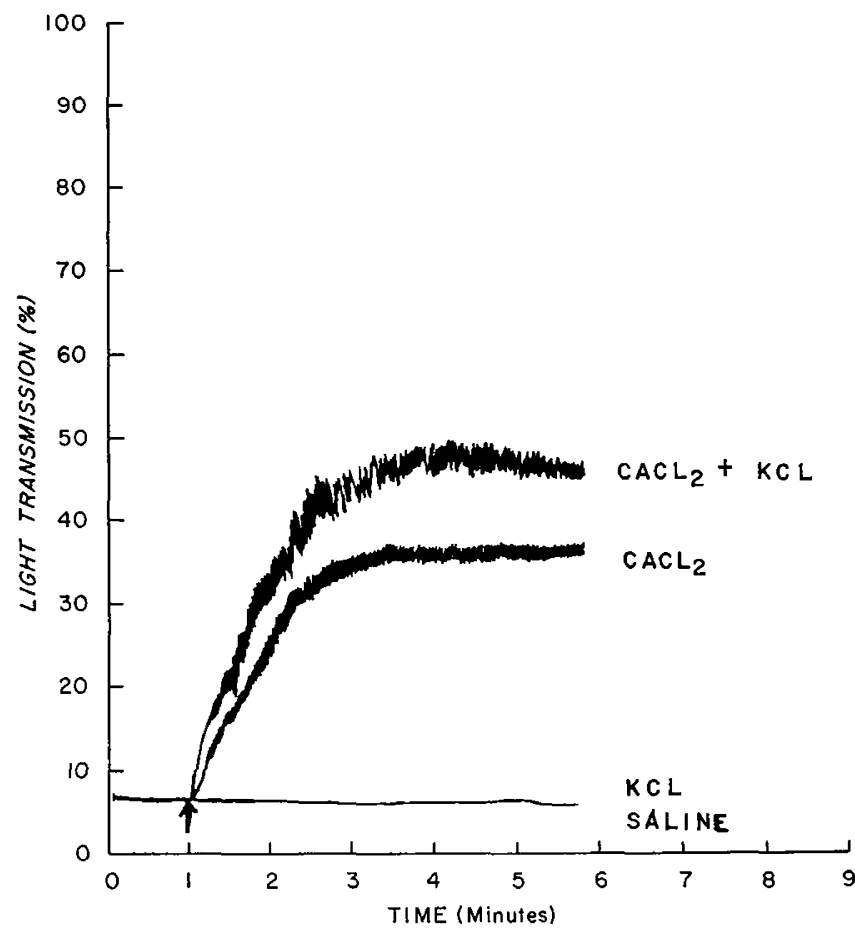

Fig. 6. The effect of ionic composition of the medium on aggregation of platelets with bilirubin. Platelet suspension was incubated for $5 \mathrm{~min}$ at $37^{\circ}$ with either $0.05 \mathrm{ml} \mathrm{KCl}(0.154 \mathrm{M}), 0.02 \mathrm{ml}$ $\mathrm{CaCl}_{2}(0.11 \mathrm{M})$, or both, before the addition of $0.1 \mathrm{ml}$ bilirubin (final concentration $4 \mathrm{mg} / 100 \mathrm{ml}$ ) or Tris-buffered saline, $\mathrm{pH} 7.8$. Light transmission is directly proportional to platelet aggregation.
The data presented indicate that small amounts of unbound unconjugated bilirubin markedly affect human platelets. Bilirubin becomes firmly attached to platelets, causing them to stain yellow, aggregate, and release adenine nucleotides. Platelets, like other cells $[10,12,29]$, are protected from the action of bilirubin (in this case, platelet staining, aggregation, and adenine nucleotide release) when bilirubin is completely bound to albumin or altered by photooxidation. Aggregation, but not staining of platelets, by bilirubin is calcium-dependent and is enhanced by potassium ions.

Since bilirubin binds plasma proteins, it may very well have the same effect on a protein receptor, on or in the platelet membrane, or within the platelet. Ganguly [14] has shown recently that albumin isolated from homogenized human blood platelets is identical with serum albumin. It may well be that bilirubin is taken up by cell membrane lipids and transferred to albumin and other proteins within the platelet. Some similar process possibly also occurs in liver cells, fat cells, epidermal cells, and neurons, although there is no evidence for such transport [1].

The amount of ADP and ATP detected in the ambient fluid after platelet suspension has been stirred with bilirubin reflects the available platelet ADP and ATP, their diffusibility through an altered membrane, and their destruction by adenosine diphosphatase and adenosine triphosphatase. The reduction in intracellular ADP and ATP and the increase in extracellular ADP and ATP after incubating bilirubin with platelet suspension indicate that unbound unconjugated bilirubin causes adenine nucleotide release from platelets. Released ADP is probably the cause of bilirubin-induced platelet aggregation.

The clinical application of the observations re-

Table I. Effect of bilirubin alone or combined with albumin on platelet nucleotide content ${ }^{1}$

\begin{tabular}{|c|c|c|c|c|}
\hline & Buffered saline & Bilirubin-albumin ${ }^{2}$ & Bilirubin ${ }^{3}$ & Significance level ${ }^{4}$ \\
\hline \multicolumn{5}{|l|}{$\mathrm{ADP}^{5}$ content } \\
\hline Platelets & $26.3 \pm 2.73$ & $26.3 \pm 2.73$ & $11.1 \pm 3.79$ & $P<0.05$ \\
\hline \multicolumn{5}{|l|}{$\mathrm{ATP}^{6}$ content } \\
\hline Platelets & $83.8 \pm 11.25$ & $83.8 \pm 11.25$ & $46.2 \pm 4.00$ & $P<0.02$ \\
\hline Supernatant fluid & $21.6 \pm 2.50$ & $21.6 \pm 2.50$ & $43.0 \pm 5.68$ & $P<0.01$ \\
\hline
\end{tabular}

${ }^{1}$ Values expressed as nanomoles per $10^{9}$ platelets and given as the mean $\pm S E$ of five determinations.

${ }^{2}$ Bilirubin, final concentration $6 \mathrm{mg} / 100 \mathrm{ml}$; bilirubin/albumin molar ratio, 0.75 .

${ }^{3}$ Final concentration $6 \mathrm{mg} / 100 \mathrm{ml}$.

4 Comparison of bilirubin-treated platelets to the other two groups. There is no significant difference $(P>0.05)$ between buffered saline and bilirubin-albumin treated platelets.

5 ADP: Adenosine diphosphate.

6 ATP: Adenosine triphosphate. 
ported here is contingent on the long term effect of unbound unconjugated bilirubin on platelets. Until it is known what such long term effects of bilirubin are on platelet aggregation, nucleotide regeneration in platelets, and ADP release, one can only speculate on the clinical significance of these findings. The described effects of bilirubin on platelets could play a role in producing intravascular thrombosis or hemorrhage, or both. In Rozdilsky's studies [32, 33] hemorrhagic lesions in the intestines, lungs, pleura, brain, and kidney were found in nearly all the animals infused with bilirubin. He postulated a direct toxic action of bilirubin on vascular endothelium, with resulting increased permeability and fragility of capillaries. In early accounts of human kernicterus, hemorrhagic complications were well known but poorly understood $[37,39]$.

More recent studies [25], to be reported fully elsewhere, have disclosed an additional effect of bilirubin on platelet function. Following the incubation of citrated human platelet-rich plasma with bilirubin at concentrations of between 15 and $25 \mathrm{mg} / 100 \mathrm{ml}$, platelet aggregation was inhibited when these platelets were challenged by ADP, noradrenalin, and connective tissue. Thus, bilirubin in a platelet-plasma system interfered with platelet aggregation produced by other agents. We interpret our data to indicate that the influence of bilirubin on platelet function is dependent largely upon the molar ratios of bilirubin/protein in the platelet suspension. When bilirubin is entirely bound to protein, its predominant effect seems to be inhibition of platelet aggregation. Once the bilirubinbinding capacity of the fluid in which the platelets are suspended is exceeded and unbound bilirubin becomes available, platelet staining and aggregation occur.

Since unbound unconjugated bilirubin at low concentration stains and aggregates platelets, and albumin-bound unconjugated bilirubin does not, a platelet system may be of value to assay free unconjugated bilirubin in jaundiced plasma. New, potentially toxic drugs which might interfere with albumin binding of bilirubin may also be screened [24].

\section{References and Notes}

1. Behrman, R. E., AND Hsia, Y. Y.: Summary of a symposium on phototherapy for hyperbilirubinemia. In: D. Bergsma and Y. Y. Hsia: Bilirubin Metabolism in the Newborn. Birth Defects: Original Article Series, Vol. 6, no. 2, p. 131. (Williams \& Wilkins, Baltimore, 1970).

2. Behrman, R. E., ANd Hubbard, E.: Bilirubin: acute effects in newborn rhesus monkeys. Science, 144: 545 (1964).

3. Blondhiem, S. H., Lathrop, D., and Zabriske, J.: Effect of light on the absorption spectrum of jaundiced serum. J. Lab. Clin. Med., 60: 31 (1962).

4. BorN, G. V. R.: Aggregation of blood platelets by adenosinc diphosphate and its reversal. Nature, 194: 927 (1962).

5. Cheung, W. H., Sawitsky, A., and Isenberc, H. O.: The effect of bilirubin on the mammalian erythrocyte. Transfusion, 6: 475 (1966).

6. Corby, D. G., Zirbel, C. L., Gibson, M. S., and Schulman, I.: Effect of antenatal drug administration on aggregation of platelets of newborn infants. In: Abstracts of the Society for Pediatric Research, p. 17. Atlantic City, N.J., 1970.

7. Corti, R.: Personal communication (Westinghouse, Bloomfield, N.J.).

8. Cowger, M. L., Igo, R. P., ANd Labre, R. F.: Mechanism of bilirubin toxicity studied with purified respiratory enzyme and tissue culture systems. Biochemistry, 4: 2763 (1965).

9. DAY, R.: Inhibition of brain respiration in vitro by bilirubin. Reversal by various means. Proc. Soc. Exp. Biol. Med., 85: 261 (1954).

10. Diamond, I., AND SCHMID, R.: Experimental bilirubin encephalopathy. The mode of entry of bilirubin ${ }^{14} \mathrm{C}$ into the central nervous system. J. Clin. Invest., 45: 678 (1966).

11. Diamond, I., ANd Schmid, R.: Oxidative phosphorylation in experimental bilirubin encephalopathy. Science, 155: 1288 (1967).

12. DIAMOND, I., ANd SCHMid, R.: Neonatal hyperbilirubinemia and kernicterus; experimental support for treatment by exposure to visible light. Arch. Neurol., 18: 699 (1968).

13. GaArder, A., Jonsen, J., Laland, S., Hellem, A., and Owren, P. A.: Adenine diphosphate in red cells as a factor in the adhesiveness of human blood platelets. Nature, 192: 531 (1961).

14. Ganguly, P.: Studies on platelet proteins. III. The identity of platelet and serum albumin. Biochim. Biophys. Acta, 188: 78 (1969).

15. Hast.Am, R. J.: Role of adenosine diphosphate in the aggregation of human-blood platelets by thrombin and by fatty acids. Nature, 202: 765 (1964).

16. Haslam, R. J.: Mechanisms of blood platelet aggregation. In: S. A. Johnson and W. H. Seegers: Physiology of Hemostasis and Thrombosis, p. 88. (Charles C Thomas, Springfield, IIl., 1967).

17. HASLAM, R. J.: Biochemical aspects of platelet function. In: E. R. Jaffe.: Plenary Session Papers, p. 95. XII Congress International Society of Hematology, New York, 1968.

18. Hellem, A. J.: Platelet adhesiveness. Scand. J. Haematol., 1: 99 (1968).

19. Horowitz, H. I., Cohen, B. D., Martinez, P., and PapayoaNou, M. F.: Defective ADP-induced platelet factor 3 activation in uremia. Blood, 30: 331 (1967).

20. KabAr, E. A., ANd MAYers, M. M.: Experimental Immunochemistry, p. 476. (Charles C Thomas, Springfield, Ill. 1967).

21. LabBe, R. F., Zaske, M. R., AND AldRICH, R. A.: Bilirubin inhibition of heme biosynthesis. Science, 129: 1741 (1959).

22. Malloory, H. T., and Evelyn, K. A.: The determination of bilirubin with the photoelectric colorimeter. J. Biol. Chem., 119: 481 (1937).

23. Marcus, A. J.: Platelet function. I. and II. New Engl. J. Med., 280: 1213 and 1278 (1969).

24. Maurfr, H. M., ANd Caul, J.: Drug interference with albumin binding of bilirubin: new platelet assay. In: Abstracts of 
The Society for Pediatric Research, p. 213. Atlantic City, N.J., 1970.

25. Maurer, H. M., and Caul, J.: Platelet aggregation: effects of bilirubin. In: Abstracts of the American Society of Hematology, p. 127. San Juan, Puerto Rico, 1970.

26. Maurer, H. M., Still, W. J. S., Caul, J., Valdes, O. S., and Laupus, W. E.: Familial bleeding tendency associated with microcytic platelets and impaired relcase of platelet adenosine diphosphate. J. Pediat., 78: 86 (1971).

27. Mustafa, M. G., Cowger, M. L., ANd KING, T. E.: Effect of bilirubin on mitochondrial reactions. J. Biol. Chem., 244: 6403 (1969).

28. Odelr., G. B.: Studies in Kernicterus. X. The protein binding of bilirubin. J. Clin. Invest., 38: 823 (1959).

29. Odeli., G. B.: The distribution of bilirubin between albumin and mitochondria. J. Pediat., 68: 164 (1966).

30. Oski, F. A., and Naiman, J. L.: Red cell binding of bilirubin. J. Pediat. 63: 1034 (1963).

31. Ostrow, J. D., AND SCHmid, R.: Protein binding of $\mathrm{C}^{14}$-bilirubin in human and murine serum. J. Clin. Invest., 42: 1286 (1963).

32. Rozdilsky, B.: Experimental studies on the toxicity of bilirubin. In: A. Sass-Kortsak: Kernicterus, p. 161. (University of Toronto Press, Toronto, 1961).

33. Rozdilsky, B.: Toxicity of bilirubin in adult animals. An experimental study. Arch. Pathol., 72: 8 (1961).

34. Schanker, S., McCandless, D. W., and Zollman, P. E.: Studics of cellular toxicity of unconjugated bilirubin in kernicteric brain. J. Clin. Invest., 45: 1213 (1966).

35. Schutta, H. S., Johnson, L., And NeIville, H. E.: Mitochondrial abnormalities in bilirubin encephalopathy. J. Neuropathol. Exp. Neurol., 29: 296 (1970).

36. Suvansri, U., Cheung, W. H., And Sawrtsky, A.: The effect of bilirubin on the human platelet. J. Pediat., 74: 240 (1969).
37. Vaughan, V.: Kernicterus and erythroblastosis fetalis. J. Pediat., 29: 462 (1946).

38. Zetrerstrom, R., and ERnster, L.: Bilirubin as uncoupler of oxidative phosphorylation in isolated mitochondria. Nature, 178: 1335 (1956).

39. Zeulzer, W. W., and Mudgett, R. T.: Kernicterus: etiologic study based on an analysis of 55 cases. Pediatrics, 6: 452 (1950).

40. RC-2B, Ivan Sorvall, Inc., Norwalk, Conn.

41. Siliclad, Clay-Adams, New York, N. Y.

42. Tris (hydroxymethyl) amino methane, Fisher Scientific Company, Washington, D.C.

43. Chrono-Log Corporation, Broomall, Penna.

44. Model EU-20V, Heath Company, Benton Harbor, Mich.

45. Fisher Scientific Company, Washington, D.C.

46. Hyland Division, Travenol Laboratories, Inc., Costa Mesa, Calif.

47. F20T12/B, Westinghouse, Bloomfield, N.J.

48. Model 15, Carey, Monrovia, Calif.

49. Boehringer und Soehne GmbH, Mannheim, Germany.

50. Sigma Chemical Company, St. Louis, Mo.

51. The authors are indebted to Dr. Clare N. Shumway and Mrs. Linda Thornton for advice and assistance in this study, and to Mrs. Elaine Gubbins, of the Department of Biometry, for performing the statistical analyses.

52. Presented in part at a mecting of The Society for Pediatric Research, Atlantic City, N.J., May 2, 1970.

53. Statistical analyses were supported, in part, by Public Health Research Grant RR 00016-08, from the National Institutes of Health.

54. Requests for reprints should be addressed to: Harold $M$. Maurer, M.D., Department of Pediatrics, Medical College of Virginia, Health Sciences Division, Virginia Commonwealth University, Richmond, Va. 23219 (USA).

55. Acceptcd for publication April 27, 1971. 